\title{
Gümüşhane İli İçin Bisiklet Ulaşımı Planlaması
}

\author{
Ömer Faruk ÖZTÜRK ${ }^{1}$ D, Emine ÇORUH ${ }^{2 *}$ (D) \\ ${ }^{1}$ Giresun Üniversitesi, Tirebolu Mehmet Bayrak Meslek Yüksekokulu, Ulaştırma Hizmetleri Bölümü, \\ Giresun, Türkiye \\ ${ }^{2 *}$ Gümüşhane Üniversitesi, Mühendislik ve Doğa Bilimleri Fakültesi, İnşaat Mühendisliği Bölümü, \\ Gümüşhane, Türkiye
}

Geliş / Received: 1.11.2018, Kabul / Accepted: 9.10.2019

$\ddot{O} \mathbf{z}$

$\mathrm{Bu}$ çalışmanın amacı, bisikletin bir ulaşım aracı olarak kullanılabilmesi için Gümüşhane kent merkezinde 10.500 metrelik bir bisiklet yolu tasarlamaktır. Kentin özellikleri ve mevcut ulaşım ağ yapısı göz önünde bulundurularak bir güzergâh belirlenmiştir. Seçilen güzergâh boyunca; bisiklet yollarının tasarımı yapılarak uygulama projeleri ve yaklaşık maliyetleri hazırlanmıştır. Ayrıca, şehir merkezi ve üniversite kampüsünü kapsayan yüz yüze bir anket çalışması yapılmıştır. Anket kapsamında, halkın bisiklet kullanma alışkanlığı, bisiklet sürmenin yararları hakkındaki görüşleri ve önündeki engeller öğrenilmeye çalışılmıştır. Anket sonuçlarının Ki-Kare ve Phi-Cramer V testleri ile değerlendirilmesi sonucunda, katılımcıların cinsiyeti ile bisiklet kullanımı, eğitim düzeyi ile bisiklet kullanımı ve bisikleti tanımlaması arasında önemli ilişkiler bulunmuştur. Tasarlanan bisiklet yolu inşaat imalatlarının maliyeti 2.740.900 Türk Lirası (TL) olup tek şeritli bir karayolu maliyeti ile kıyaslandığında yaklaşık üç kat daha az bulunmuştur. Sonuç olarak, bisiklet kullanımının sağlıklı, güvenli, ekonomik, çevre dostu ve kolay erişilebilir olduğu ortaya çıkmıştır. Bu özelliklerinden dolayı bisiklet kullanımının sürdürülebilir ulaşım için kentsel ulaşım sorunlarına en önemli çözümlerden biri olduğu görülmüştür.

Anahtar Kelimeler: Bisiklet, bisiklet yolu, Gümüşhane, kent içi ulaşım, anket, Ki Kare ve Phi-Cramer V Testleri

\begin{abstract}
Abctract
The aim of this study is to design a 10.500 meter bicycle path for the use of a bicycle as a means of transportation in Gümüşhane city center. A bicycle route has been identified considering the characteristics of the city and its current transportation network. The design of bicycle paths and the cost of application projects were prepared throughout the selected route. Also, a face-to-face survey was conducted covering the city center and the university campus. It has been tried to learn the opinion about the cycling habit of public, benefits of cycling and the obstacles to cycling in the city within the scope of the survey. According to Chi-square and Phi-Cramer's $\mathrm{V}$ tests the results of the survey, significant relationships were found between the gender of participants and cycling, the education level of participants and cycling, and the definition of cycling. The cost of designed bicycle path construction is 2.740 .900 Turkish Liras (TL) and was found about three times less than the cost of a single lane highway. As a result, it was found that cycling is healthy, safe, economical, environmentally friendly and easily reachable. These characteristics of cycling show that cycling for sustainable transport is one of the most important solutions to urban transportation problems.
\end{abstract}

Bicycle Transportation Planning For Gumushane Province

Keywords: Bicycle, bicycle path, Gumushane, urban transportation, survey, Ki Square and Phi-Cramer V tests 


\section{Giriş}

Ulaştırma sektörü, dünyada en fazla sera gazı (küresel 1sınmanın ana nedenlerinden biri) yayan, büyük hacimli ve maalesef hala büyümeye devam eden bir sektördür (Gaigne vd., 2012). Özellikle karayolu taşımacılığ ulaşım sektöründe üretilen sera gazlarının büyük bir çoğunluğundan mesuldür. Örneğin ABD'de, sera gazı emisyonlarının yaklaşık \% 60'inin (bu oran 1990' lardan 2006'ya gelindiğinde $\% 20$ den $\% 75$ 'lere çıkmıştır) özel araç kullanımı için harcanan akaryakıt tüketiminden kaynaklandığı bildirilmiştir (Environmental Protection Agency, 2011). 21. yy da tüm dünyada şehirler, ekonomik kalkınma ve hareketlilik kalıpları açısından büyük bir değişim yaşamaktadırlar (Hickman vd., 2010). Nüfus artış1, artan şehirleşme, ortalama gelir, beklenti ve tüketim, seyahat talebinin daha da artmasına yol açmaktadır. $\mathrm{Bu}$ zorlukları karşılamak için ulaşıma ayrılan bütçe ve altyapı maalesef talepteki büyümenin gerisinde kalmakta ve $\mathrm{CO}_{2}$ emisyonunun azaltılması için beklentileri karşılamamaktadır (Hickman vd., 2010). Ulaşım sektörünün gelecekte de bugünkü hali ile devam edemeyeceği açıktır özellikle sera gazı ve $\mathrm{CO}_{2}$ azalımı için daha fazla değişikliğe gitme zorunluluğu vardır (Hickman ve Banister, 2007; Hickman vd., 2010). Kent yaşamında bisiklet kullanımı, hareketsiz yaşam tarzını ve buna bağlı olarak oluşan, sağlık problemlerini önlemek adına da birçok fayda sağlar (Cervero ve Duncan, 2003; Racioppi vd., 2013; Goetschi vd., 2016; Andersen vd., 2000; Rojas-Rueda vd., 2011; Wen vd., 2011; Woodcock vd., 2011; Oja vd., 2011; Reynolds vd., 2010; Milne ve Melin, 2014). Ayrıca bisiklet, kentsel hava kirliliğini azaltarak ve petrolle ilgili (Burke ve Bonham, 2010) taşımacılığa alternatif olarak (neredeyse sıfir sera gazı emisyonu salınır, $\mathrm{CO}_{2}$ emisyonlar1 $1 \mathrm{~km}$ 'de 21 g ECF 2013) daha çevre dostu bir ulaşım sağlar (de Nazelle vd., 2011). Dolayısı ile sürdürülebilir şehirlerin oluşturulabilmesi için insanların günümüzde karşılaştıkları birçok çevresel ve sosyal sorun karşısında bisiklet, giderek daha da önemli olmaya başlamıştır (Curtis, 2008; Rojas-Rueda vd., 2011). Bisiklet ayrıca, insan için kent manifestosu altında yaşanabilir kent kavramı için de enerji verimliliği, çevre dostu olması ve toplu taşıma ile uyumluluğu gibi özellikleri nedeniyle önemli bir ulaşım türü olarak kabul edilmektedir (Öztürk, 2018). Araştırmacılar, mevcut altyapı ile seyahatlerin \%40'ının arabasız gerçekleştirilebileceğini ve altyapıya yapılacak çok az yatırım ile bu oranın \%80'e çıkarılabileceğini tahmin etmektedirler (Brög ve John, 2001). Gelişmiş ülkelerin birçoğunda ulaşım planlamacıları ve trafik mühendisleri kent içi ulaşımda sırasıyla yaya yollarının, bisiklet yollarının, raylı sistemlerin, diğer toplu taşıma araçlarının ve en son olarak özel araçların tercih edilmesi gerektiği düşüncesini savunmaktadır. Yeşil ulaşım türleri diye adlandırılan yaya ve bisiklet kullanımı özellikle gelişmiş ülkelerde sürdürülebilir ve çevre dostu ulaşım olarak hem yerel hem de merkezi yönetimlerce desteklenmektedir (Öztürk, 2018). Türkiye'de özellikle son 20 y1l içerisinde birçok araștırmacı bisikletin hem sürdürülebilir kent anlayışı için önemini hem de sağlık açısından sayısız faydasını vurgulamıştır. Ek olarak bisikletli ulaşımı etkileyen olumsuzlukları tanımlamış ve çözüm önerilerinde bulunmuşturlar (Öncü, 1990; İyinam ve İyinam, 1999; Ulvi, 2002; Uz ve Karaşahin, 2004; Koçak vd., 2005; Kaplan 2005, 2009, Akay, 2006; Çiftçi, 2006; Uslu vd., 2009; Mert ve Öcalır, 2010; Elbeyli, 2012; Çalışkan, 2013; İmamoğlu vd., 2014; Levent, 2014; Ardahan ve Mert, 2014 a, b; Çeyiz ve Koçak, 2015; Cengiz ve Kahvecioğlu, 2016; Koçak, 2016; Yakar vd., 2017). 
Türkiye'de 03.11.2015 tarih ve 29521 say1l resmi gazetede "Şehir İçi Yollarda Bisiklet Yolları, Bisiklet İstasyonları ve Bisiklet Park Yerleri Tasarımına ve Yapımına Dair" bir yönetmelik yayımlanmıştır. Bu yönetmeliğin amacının, şehir içi yollarda bisikletin bir ulaşım aracı olarak kullanılmasının sağlanması olduğu bildirilmiştir. İlgili yönetmeliğin amacı çerçevesinde de bu çalışmanın, Gümüşhane ve diğer iller için örnek bir çalışma olarak katkı sağlayacağı düşünülmektedir.

\subsection{Gümüşhane İli Genel Özellikleri}

Dünya'nın birçok şehrinde olduğu gibi Gümüşhane'de de son yıllarda nüfusun hızla artmasından ve hızlı kentleşmeden dolayı birçok ulaşım problemi ortaya çıkmıştır. Günümüzde insanlar her ne kadar toplu taşımaya yönlendirilmeye çalışılsa da otomobil sahipliğinin getirdiği rahatlık, kapıdan kapıya esnek taşıma ve otomotiv sektöründeki teknolojik gelişmeler tüm dünyada olduğu gibi Türkiye'de ve Gümüşhane'de de insanların ulaşım ihtiyaçlarını özel araç ile gerçekleştirmelerine sebep olmaktadır (Öztürk, 2018). İnsanların özel araçla ulaşıma yönelmesi ve artan araç sahipliliği oranları, trafikte artan araç sayısı, trafik sıkışıklığı ve park sorunu gibi birçok problemi beraberinde getirmektedir. Gümüşhane' de nüfusun diğer illere nazaran çok fazla olmamasına rağmen artan özel araç sahipliliği, zorlu ve sınırlandırılmış bir topoğrafyaya sahip şehir için söz konusu problemlerin meydana gelmesinde önemli bir rol oynamaktadır. Artan araç sayısına bağlı olarak bazı caddelerdeki araç yoğunluğu Şekil 1'de gösterilmiştir (Öztürk, 2018).

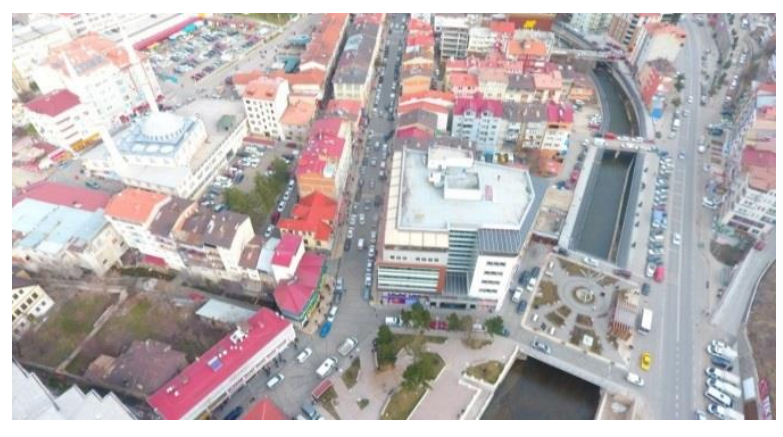

Şekil 1. Gümüşhane İli Atatürk ve İnönü Caddelerinden Bir Görüntü

Şehrin ana arterini oluşturan karayolu (E97) yakın zamana kadar transit trafiğge de hizmet vermiştir. Mevcut karayolunun etrafındaki düzensiz yapılaşma, çift taraflı parktan dolayı yer yer daralma ve kamulaştırma sorunlarının genişletme çalışmalarının yapılmasına müsaade etmemesi, şehrin ilk etapta gözlemlenen başlıca ulaşım sorunlarıdır. Ayrıca Gümüşhane ilinde gerek coğrafi kısıtlardan gerekse yapılan yatırımların sadece karayoluna yönelik olmasından dolayı insanlar, ulaşım ihtiyaçlarını sadece tek modla (karayolu ile) karşılamaktadırlar (Öztürk, 2018). Emniyet Genel Müdürlüğü verilerine göre Gümüşhane il genelinde ehliyetli kişi sayısı 54.455 ve motorlu araç sayısı 24.144'tür. Gümüşhane kent merkezinde ise motorlu araç sayısı 10.433'tür. Nüfus ile orantılı bir hesap yapıldığında Gümüşhane kent merkezinde her üç aileden ikisinin özel araç sahibi olduğu anlaşılmaktadır (Öztürk, 2018).

\section{Materyal ve Metot}

Bu çalışma ile Gümüşhane ilinde bisikletin bir ulaşım aracı olarak kullanılması ve kent genelinde yaygınlaşması için Gümüşhane'nin kentsel özellikleri ve mevcut ulaşım ağ yapısı da göz önünde bulundurularak, bisikletli ulaşım açısından kent değerlendirilmiş ve kent merkezini kapsayan bir bisiklet yolu tasarımı yapılmıştır. Uygulamaya esas bisiklet yolu güzergâh1; Erzurum-Trabzon karayolu 
(E97) kenarı olarak belirlenmiştir. Güzergâh seçiminin en etkili sebeplerinden ilki Gümüşhane il merkezinin dağlık bir araziye sahip olması ve buna bağlı olarak şehrin Erzurum-Trabzon karayolu (E97) boyunca paralel kurulmuş olmasıdır. İkinci sebep ise mevcut durumla birlikte Gümüşhane'de artan öğrenci nüfusu dikkate alındığında en fazla yolcu hareketinin bu doğrultuda gerçekleşmesidir. Üçüncü sebep ise; 2018 y1lında yapımı tamamlanan ve kullanıma açılan Gümüşhane çevre yolunun, E97 karayolunun trafik hacmini azaltarak özellikle transit yol olma özelliğini kaybettirmiş olmasıdır. Önerilen güzergâh boyunca bisiklet yolu için ilgili yönetmelik, American Association of State Highway and Transportation Official (ASSHTO) ve Karayolları Genel Müdürlüğü (KGM) standartları kullanılmıştır.

Çalışmanın ikinci kısmında ise Gümüşhane il merkezi genelinde ve Gümüşhane Üniversitesi kampüsünde 2018 y1lı mart ve nisan aylarında yüz yüze anket çalışması yapılmıştır. Anket soruları ile Gümüşhane'de yaşayan halkın bisiklet kullanma alışkanlıkları, kentte bisiklet sürmenin yararları hakkındaki görüşleri ve algılanan sorunlar ayrıca bisiklet sürmenin önündeki engeller öğrenilmeye çalışılmıştır. Anket sonuçlarına Ki Kare ve Phi-Cramer V testleri uygulanarak, gruplar arasındaki anlamlı ilişkiler ortaya çıkarılmaya çalışılmıştır (Öztürk, 2018). Yapılan anket ile aşağıdaki temel amaçlar hedeflenmiştir;

1. Gümüşhane ilinde bisiklet kullanımının mevcut durumunu belirleyebilmek,

2. Halk nezdinde mevcutta var olan bisiklet yollarının (yaklaşık $1 \mathrm{~km}$ ) yeterli olup olmadığını belirleyebilmek,

3. Gümüşhane halkının özel araç sahiplilik oranını belirleyebilmek,
4. Ev/iş/okul yolculuklarında hangi ulaşım modunu tercih ettiklerini belirleyebilmek,

5. Gümüşhane'de tasarımı yapılarak önerilen bisiklet yolu projesinin uygulanması halinde, Gümüşhane halkının ve Gümüşhane Üniversitesi öğrencilerinin yolu kullanma taleplerini belirleyebilmek.

Çalışma kapsamında toplamda 611 kişi üzerinde yüz yüze anket yapılmış ve kullanilabilir olan 574 tane anket değerlendirmeye alınmıştır.

\section{Bulgular}

\subsection{Anket Çalışması Sonuçlarının Değerlendirilmesi}

Anketlerin sonuçlarına göre, katılımcıların 197 tanesi kadın, 377 tanesi erkektir. Grafik 1 'de cinsiyete göre dağılım gösterilmiştir.

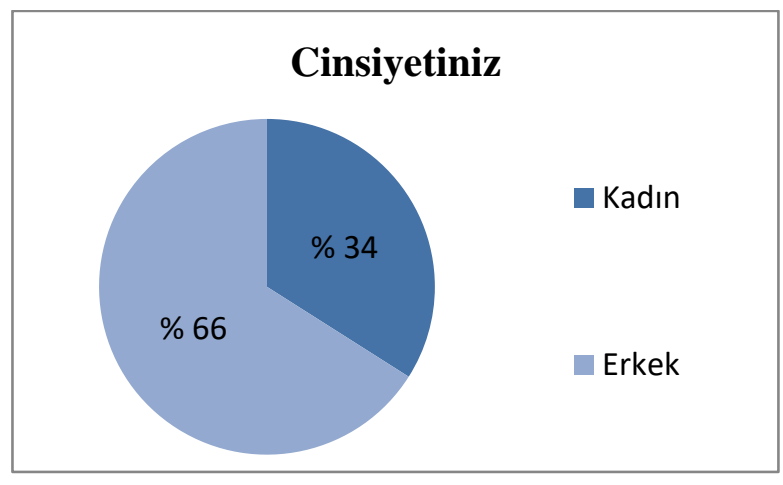

Grafik 1. Ankete Katılan Kişilerin Cinsiyete Göre Dağılımı

Katılımcılardan 51 kişi ilkokul mezunu, 94 kişi lise mezunu, 45 kişi yüksekokul mezunu ve 384 kişi üniversite öğrencisi ve/veya üniversite mezunudur. Grafik 2'de ankete katılan kişilerin eğitim durumuna göre dağglımı gösterilmiştir. 


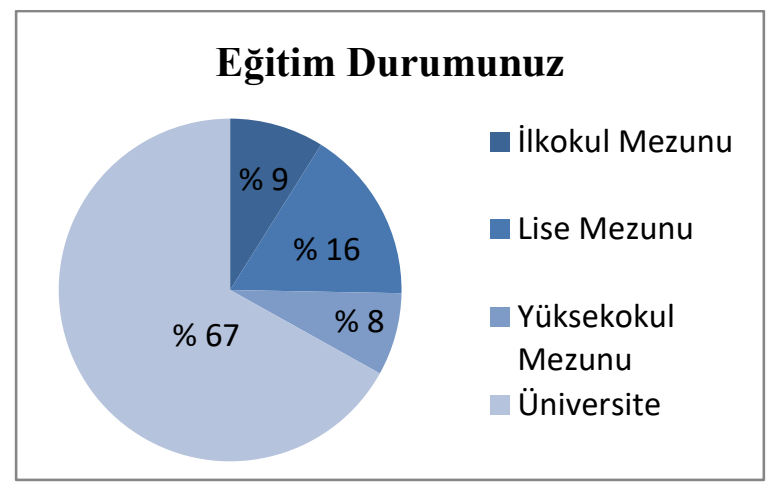

Grafik 2. Ankete Katılan Kişilerin Eğitim Durumuna Göre Dağılımı

Ankete katılanlardan 167 tanesinde bisiklet varken, geriye kalan 407 kişinin bisikleti yoktur. Grafik 3'de bisiklet sahipliliğine göre dağılım gösterilmiştir.

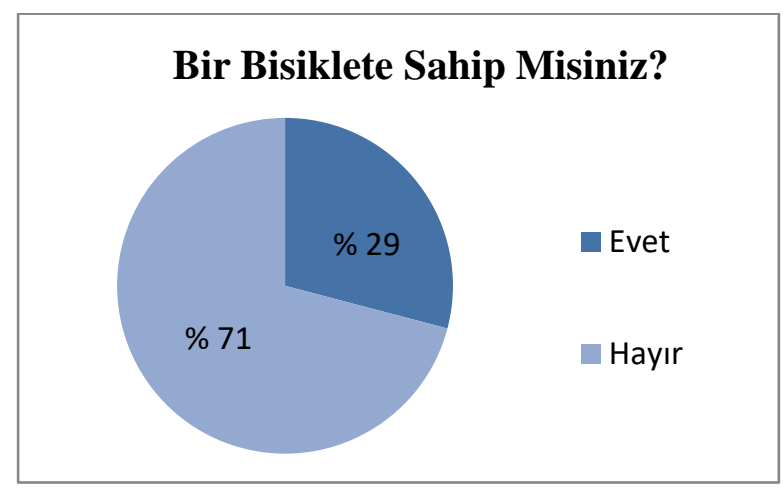

Grafik 3. Bisiklet Sahipliliğine Göre Dağılım

Katılımcıların \% 92'si gibi büyük bir kısmı (bisikletleri olsa da olmasa da) kendilerine daha fazla bisiklet kullanma imkânı sağlanmasını istemiştir. $\mathrm{Bu}$ bağlamda yapılacak olan bisiklet yolunun bisikleti olmayan insanlara da hitap etmesi amaciyla başlangıç ivmesini kazandırmak adına gerek yerel yönetimin gerekse farklı kurumların, bisiklet paylaşımı, kiralık bisiklet vb. olanakları sağlaması gerekmektedir. Tablo 1 'de bu ilişkiyi gösterir tablo verilmiştir.
Tablo 1. Bisiklet Sahipliliği İle Bisiklet Kullanma İmkânı Sağlanmasının İstenmesi Arasındaki İlişkiyi Gösteren Tablo

\begin{tabular}{|l|c|c|c|}
\hline & \multicolumn{3}{|c|}{$\begin{array}{l}\text { Bisiklet Kullanma İmkânı } \\
\text { Sağlanmasını İster Misiniz? }\end{array}$} \\
\hline $\begin{array}{l}\text { Bir Bisiklete } \\
\text { Sahip } \\
\text { Misiniz? }\end{array}$ & Evet & Hayır & Toplam \\
\hline Evet & 158 & 9 & 167 \\
\hline Hayır & 371 & 36 & 407 \\
\hline Toplam & 529 & 45 & 574 \\
\hline
\end{tabular}

$\mathrm{Bu}$ çalışmanın amaçlarından biri insanların bisikleti hangi amaçla kullandıklarını/ kullanacaklarını belirlemektir. $\mathrm{Bu}$ amaca yönelik sorular incelendiğinde katılımcıların $\%$ 84'ü bisikleti spor ve gezinti aracı olarak tanımlarken \% 16'sı ulaşım aracı olarak tanımlamıştır. Ki-kare test sonuçlarına göre katılımcıların eğitim düzeyleri ile bisikleti tanımlama olabilirlik düzeyi $\% \quad 0.03$ bulunmuştur. Yine ki-kare test sonuçlarına göre katılımcıların eğitim düzeyi ile bisiklet kullanmamadaki olabilirlik düzeyi ise \% 0.04 olarak bulunmuştur. Eğitim düzeyinin bisiklet kullanma üzerindeki etkisini araştırmak için Phi-Cramer V testi yapılmış 0-1 arasında değişen değerlere göre güçlü bir ilişki saptanmıştır. Katılımcıların \% 69.7' si bisiklet kullanmamadaki en önemli sebebi "yeterli bisiklet yolu olmayışı" olarak ifade etmiştirler. İlk etapta bisikleti gerek spor gerekse gezinti amaçlı kullanacak olan insanların, getirdiği avantajlardan sonra bisikleti aynı zamanda bir ulaşım aracı olarak da kullanacağı düşünülmektedir. Böylelikle şehirdeki motorlu araç kullanımı zamanla düşecek ve insanlara daha yaşanılabilir bir çevre sunulacaktır. Grafik 4'de katılımcıların 
bisikleti tanımlamasına göre dağılım gösterilmiştir.

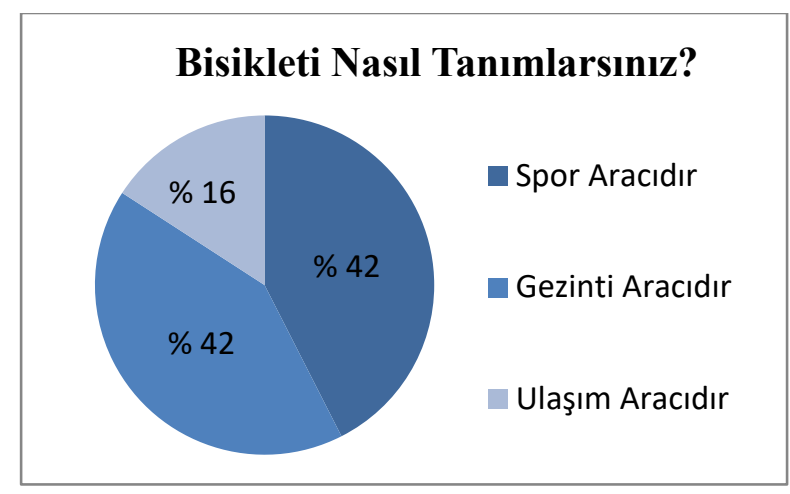

Grafik 4. Katılımcıların Bisikleti Tanımlamasına Göre Dağılım

Kat1lımciların cinsiyet ile bisiklet kullanmaması arasındaki en önemli sebepler arasında ki kare testi yapılmış ve olabilirlik düzeyi \% 0.00 çıkmıştır. Bu değerin 0.05 'den küçük olması ile katılımcıların cinsiyetleri ile bisiklet kullanmama tercihleri arasında istatistiksel olarak anlamlı bir ilişki olduğu tespit edilmiştir. Aralarındaki ilişki saptandiktan sonra cinsiyetin bisiklet kullanmama üzerindeki etkisini araştırmak için Phi-Cramer V testi yapılmıştır (Cinsiyet, bisiklet kullanmama davranışı üzerinde ne kadar büyük (veya güçlü) bir etkiye sahiptir?" sorusunun cevabı bu test ile belirlenmiştir). Cinsiyetin bisiklet kullanmamayı güçlü bir şekilde etkilediği belirlenmiştir.

Yine anket sonuçlarına göre kadınların $\% 71$ 'inin, erkeklerin ise \% 69'unun bisiklet kullanmamadaki en önemli sebepleri, yeterli bisiklet yolu olmayışıdır. Bisiklet kullanırken kendini güvende hissetmeyen katılımciların \% 7.1'i kadın, \% 6.6's1 ise erkektir. Bisiklet kullanmama sebebini kötü hava şartlarına bağlayan katılımcıların \% 5'i kadın, \% 17.7'si erkektir. Ayrıca kadınların \% 5'i ve erkeklerin \% 3.4'ü bisiklet kullanırken başkalarının kendilerini görmesinden rahatsız olmaktadır. Bisiklet kullanmayı bilmediği için bisikleti tercih etmeyen katılımciların \% 11.7'si kadın, $\%$ 3.2'si ise erkektir. Tablo 2'de katılımcıların cinsiyeti ile bisiklet kullanmamasındaki en önemli sebep arasındaki ilişki verilmiştir.

Tablo 2. Cinsiyet İle Katılımciların Bisiklet Kullanmamasındaki En Önemli Sebep Arasındaki İlişkiyi Gösteren Tablo

\begin{tabular}{|l|c|c|c|}
\hline & \multicolumn{3}{|c|}{ Cinsiyetiniz } \\
\hline $\begin{array}{l}\text { Bisiklet } \\
\text { Kullanmamada } \\
\text { En Önemli } \\
\text { Sebebiniz } \\
\text { Nedir? }\end{array}$ & Kadın & Erkek & Toplam \\
\hline $\begin{array}{l}\text { Yeterli Bisiklet } \\
\text { Yolu Yok }\end{array}$ & 140 & 260 & 400 \\
\hline $\begin{array}{l}\text { Bisiklet } \\
\text { Kullanırken } \\
\text { Kendimi } \\
\text { Güvende } \\
\text { Hissetmiyorum }\end{array}$ & 14 & 25 & 39 \\
\hline $\begin{array}{l}\text { Kötü Hava } \\
\text { Şartları }\end{array}$ & 10 & 67 & 77 \\
\hline $\begin{array}{l}\text { Bisiklet } \\
\text { Kullanırken } \\
\text { Başkalarının } \\
\text { Beni } \\
\text { Görmesinden } \\
\text { Rahatsız } \\
\text { Oluyorum }\end{array}$ & 10 & 13 & 23 \\
\hline $\begin{array}{l}\text { Bisiklet } \\
\text { Kullanmayı } \\
\text { Bilmiyorum }\end{array}$ & 23 & 12 & 35 \\
\hline $\begin{array}{l}\text { Toplam } \\
\text { Ölat }\end{array}$ & & 377 & \\
\hline & & & \\
\hline
\end{tabular}

Anket sonuçlarına göre; Gümüşhane'de tasarıma söz konusu olan bisiklet yolu yapılırsa bu yolu kullanıp kullanmayacakları sorusu ile bir bisiklete sahip olup olmama durumları karşılaştırılmıştır. Tablo 3'de gösterilmiş olan bilgilere göre bisiklete sahip olan insanların \%84'ü, bisiklete sahip olmayan insanların ise \%82'si yapılacak olan bisiklet yolunu kullanacaklarını ifade etmiştir. Ayrica bisikleti olmayan 407 kişinin 333'ünün yapılacak olan bisiklet yolunu 
kullanacakları yönünde beyanda bulunması, bisiklet yolunun motorlu ulaşıma bir alternatif olarak halk tarafindan benimsenmesinin bir göstergesi olarak uygun politikalar üretmek için kullanılabilir.

Tablo 3. Bisiklet Yolu Yapılması Halinde Bu Yolun Kullanılma Durumununa Göre Dağılım

\begin{tabular}{|l|c|c|c|}
\hline & \multicolumn{3}{|c|}{ Bisiklet Yolu Yapılsa Bu Yolu } \\
& \multicolumn{3}{|c|}{ Kullanır Mısını? } \\
\hline $\begin{array}{l}\text { Bir Bisiklete } \\
\text { Sahip } \\
\text { Misiniz? }\end{array}$ & Evet & Hayır & Toplam \\
\hline Evet & 141 & 26 & 167 \\
\hline Hayır & 333 & 74 & 407 \\
\hline Toplam & 474 & 100 & 574 \\
\hline
\end{tabular}

Gümüşhane ili dağlık arazisinden ve çarpık yapılaşmasından dolayı yeteri kadar otopark alanına sahip değildir. Grafik 5'te katılımcıların \% 83'ü Gümüşhane ilinde trafik veya otopark problemleri olduğunu düşünerek bilinen bu gerçeğe pozitif yönde katk1 sağlamıştır.

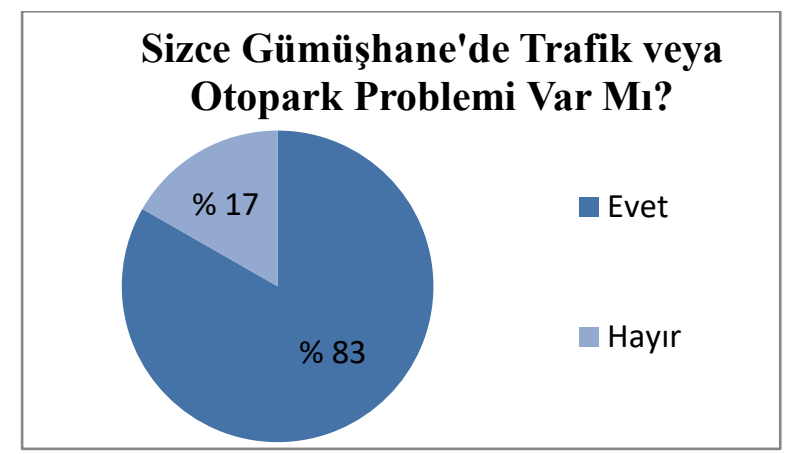

Grafik 5. Trafik veya Otopark Problemini Gösteren Grafik

Yapılan ankette katılımcılara trafik ve/veya otopark problemlerini çözmek adına bisikletli ulaşımın bir çözüm olup olmadığı sorusu yöneltilmiştir. Grafik 6'da görüleceği üzere \%78'lik kısmından trafik veya otopark probleminin çözümünde bisikletin katkısı olacağ1 yönünde cevap alınmıştır.

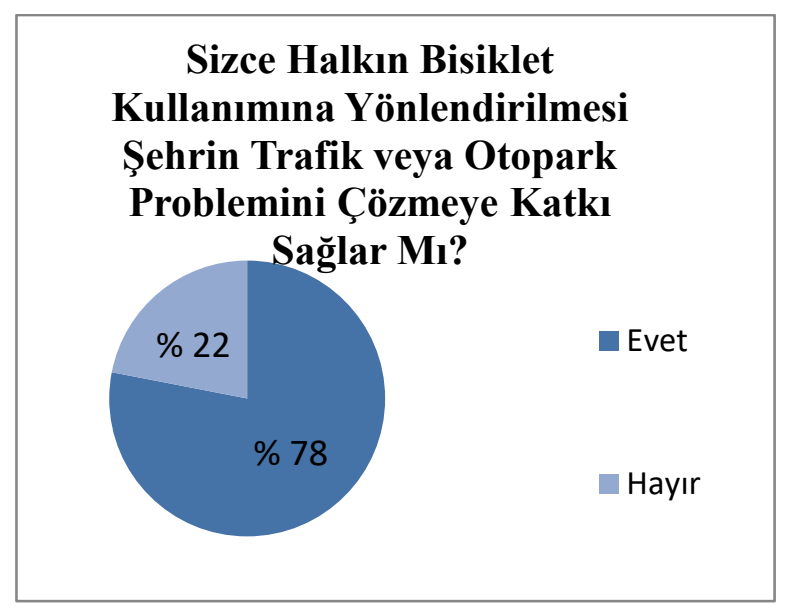

Grafik 6. Trafik veya Otopark Probleminde Bisikletin Rolünü Gösteren Grafik

Diğer \%22'lik kısım ise bu problemlerin çözümünde bisikletin bir çözüm olmayacağını ifade etmiş ve bunun için farklı şu fikirleri ileri sürmüşlerdir; şehirde daha fazla otopark alanının oluşturulması, halkı özel araç kullanımından uzaklaştıracak farklı uygulamaların yapılması, trafik ve uygun olmayan park denetiminin arttırılması ve insanların toplu taşımaya yönlendirilmesi gerektiği gibi.

\subsection{Gümüşhane İlinde Uygulamaya Esas Bisiklet Yolu Tasarımı ve Projesi}

Önerilen bisiklet yolu güzergâhında (Erzurum-Trabzon karayolu (E97) kenar1) uygulanacak proje tasarımında ölçüt olarak kullanılan yönetmelik ve standartlar, gerekli güvenlik önlemlerinin alınması halinde bisiklet yollarının karayolu (taşıt hızının 50 $\mathrm{km} / \mathrm{sa}$ ' ten fazla olan araç yolu) kenarına tesis edilmesine müsaade etmektedir. Şekil 2'de alınabilecek güvenlik önlemlerine ilişkin bir örnek enkesit gösterilmiştir.

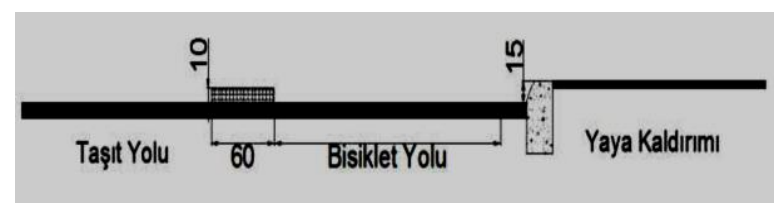

Şekil 2. Taşıt Yolundaki Bisiklet Yolunun Refüjle Ayrilmas1 
Bir diğer güvenlik önlemi ise taşıt yolu ile bisiklet yolu arasına $150 \mathrm{~cm}$ genişliğinde yeşil bant uygulaması yapılmasıdır (Şekil 3a-4a). Tamamı merkez ilçe sınırları içerisinde yer alan ve toplamda 10.500 metre olan bir bisiklet yolu tasarlanmıştır. Bu yolun 8.300 metresi 1 No'lu güzergâh olarak adlandırılan, Erzurum-Trabzon karayolu (E97) kenarına planlanmıştır. 2 No' lu güzergâh olarak adlandırılan 1.700 metrelik diğer kısım ise Atatürk Caddesi, Cumhuriyet Caddesine (bu caddeler şehir içerisinde ve yolcu hareketinin en fazla olduğu bölgededirler) ve şehir merkezi ile karayolu kenarı arasındaki bağlantı yollarına $(500 \mathrm{~m})$ tasarlanmıştır. İlgili yönetmeliğin 8 . maddesinde dikkate alınması gereken boyuna eğim Tablo 4' deki gibi gösterilmiştir.

Tablo 4. Boyuna Eğim - Mesafe Tablosu

\begin{tabular}{|c|c|}
\hline Ĕ̆im (\%) & $\begin{array}{c}\text { Önerilen Maksimum } \\
\text { Uzunluk (m) }\end{array}$ \\
\hline $5-6$ & 240 \\
\hline 7 & 120 \\
\hline 8 & 90 \\
\hline 9 & 60 \\
\hline 10 & 30 \\
\hline$>11$ & 15 \\
\hline
\end{tabular}

Güzergâh başlangıcı kotu 1119.00 metre, güzergâh son kotu ise 1183.50 metredir. Dolayısı ile güzergâhtaki boyuna eğim değeri $\% 0.70$ ' ile kesintisiz ve rahat bir bisiklet sürüşü için ideal bir eğim olup standartlara da uygundur. Şekil 3 ve Şekil 4' te 1 ve 2 No'lu güzergâh, Şekil 3-a'da 1 No'lu güzergâhta önerilen tasarım, Şekil 4-a'da ise 2 No'lu güzergâhta önerilen tasarım verilmiştir.

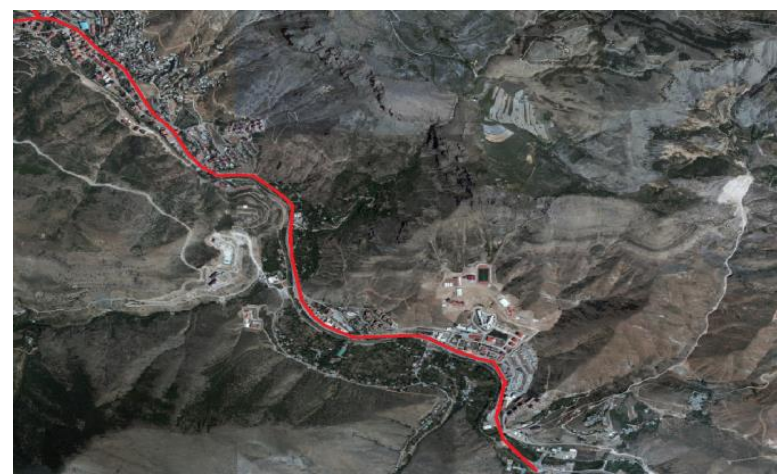

Şekil 3. Güzergâhların 1. Kısmına Ait Ortofoto Görüntü

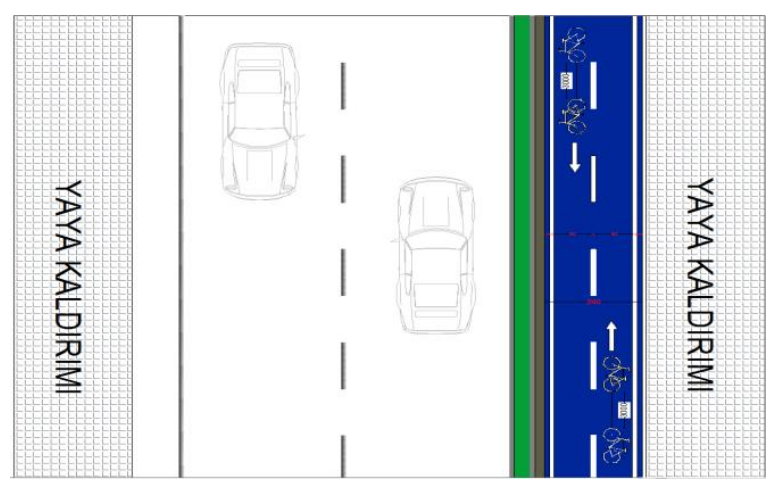

Şekil 3.a. 1 No'lu Güzergâhta Tasarlanan Bisiklet Yolu Planı

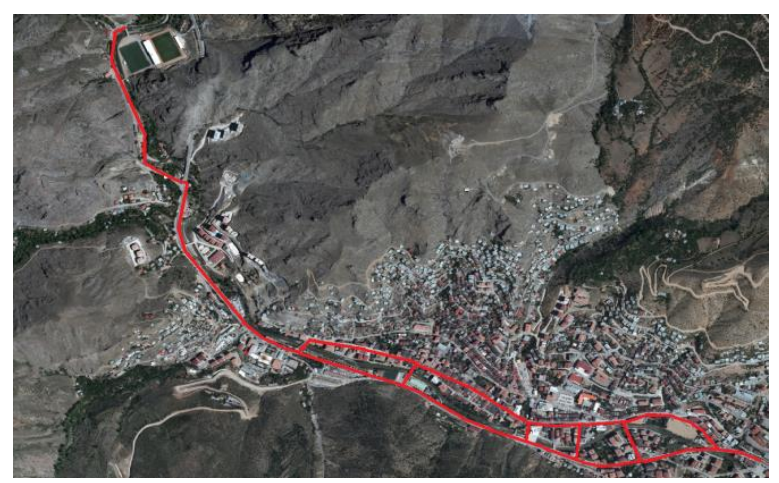

Şekil 4. Güzergâhların 2. Kısmına Ait Ortofoto Görüntü 


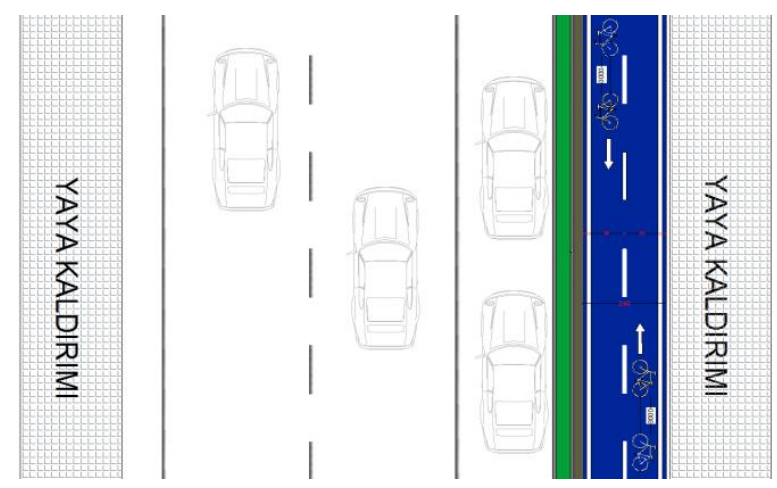

Şekil 4.a. 2 No'lu Güzergâhta Tasarlanan Bisiklet Yolu Planı

Şekil 3-a ve Şekil 4-a'da çift şerit olarak tasarlanan bisiklet yolu genişliği $240 \mathrm{~cm}$, taşıt yolu ile bisiklet yolu arasına güvenlik için uygulanması gereken yeşil bant genişliği ise 150 cm'dir. Yeşil bant uygulamasının yapılamayacağ 1 kısımlarda ise $60 \mathrm{~cm}$ genişliğinde refüj uygulaması ile güvenli bir sürüş yine sağlanabilir. Bisikletlilerin sıklıkla kullanacağı bisiklet park yerleri ve özellikle bisiklet kiralama için kullanılacak olan bisiklet istasyonları, diğer ulaşım araçlarına bütünleşmiş olacak şekilde tasarlanmış ve insanların rahatça erişebileceği yerler dikkate alınmıştır (Öztürk, 2018). Bu park yerleri ve kiralama istasyonları akıllı sistemler ile yönetilecek şekilde tasarımda önerilerde bulunulmuştur. Tasarlanan bu bisiklet yolu yapım işinin, inşaat imalatlarının tutarı 2.740.900 Türk lirasıdır. 2017 yılı birim fiyatlarına göre $10 \mathrm{~km}$ uzunluğunda tek şeritli bir karayolu inşa etmenin bedeli ise yaklaşık 8.000.000 Türk lirasıdır. Dolayısı ile tasarlanan bu bisiklet yolunun maliyeti, tek şeritli bir karayolunun maliyetinden yaklaşık 3 kat daha azdır (Öztürk, 2018).

\section{Sonuç ve Tartışma}

$\mathrm{Bu}$ çalışma kapsamında 611 adet anket yapılmış ve 574 anket değerlendirmeye alınmıştır. Gruplar arasında Ki Kare ve PhiCramer testleri yapılarak, katılımciların cinsiyeti ile bisiklet kullanımı, eğitim düzeyi ile bisiklet kullanımı ve eğitim düzeyi ile bisikleti tanımlaması arasında anlamlı ilişkiler bulunmuştur. Anket sonuçlarına göre; bisiklet yollarının tesis edilmesi halinde bu ulaşım türünün tercih edileceği ve ildeki mevcut trafik ve otopark problemlerinin çözümünde bisikletli ulaşımın, pozitif yönde katkı sağlayacağı sonucuna varılmıştır. $\mathrm{Bu}$ tasarımın uygulanması halinde ilde tek seçenek olan motorlu ulaşıma alternatif bir mod eklenecek aynı zamanda daha sağlıklı bir yaşam desteklenerek, il ölçeğinde olsa dahi kullanılan fosil yakıt miktarında düşüş meydana gelecektir. Yine söz konusu tasarımın uygulanması ile kent içi ulaşım ağı bisiklet ulaşım rotasıyla bütünleştirilerek daha kaliteli ve sürdürülebilir bir kent yaşamının sağlanması mümkün olacaktır. Nüfus artışı ve kentleşmeden dolayı 2050 yılına kadar dünyadaki kentsel nüfusa, 2,5 milyar insanın katılması öngörülmektedir ve bu artışın \%90'ından fazlasının düşük ve orta gelirli ülkelerde yoğunlaşacağı tahmin edilmektedir (United Nations, 2014). Türkiye'de 1927 y1lında nüfusun \% 75,8'i kirsalda ve sadece \% 24,2'si kentsel alanlarda yaşarken, bugün bu durum tam tersine dönmüş ve 80 milyonluk ülkemizde insanlar \% 92.1'i gibi ciddi bir oranla kentlerde yaşamaya başlamıştır (TÜIKK, 2016). Tüm dünyada olduğu gibi Türkiye'de de şehir içi ulaşımda araç kullanım payı bu rakamlardan da anlaşılacağı üzere sürekli artarak, toplumları maalesef araba bağımlılıkları ile karakterize edildiği noktaya ulaştırmıştır (Dupuy, 1999; Newman ve Kenworthy, 1989). Bu bağımlılık şehirlerde yüksek oranda araba sahipliği ve arabaların kitlesel kullanımı (trafik sıkışıklığı, uzun trafikte kalma süreleri vb.) ile kendini göstermektedir (Collet vd., 2012). Bu bilgiler 1şı̆̆ında kentlerin hâlihazırdaki ulaşım planlarının, insanların sosyal ve kültürel ihtiyaçları da göz önünde bulundurarak daha yaşanılabilir bir çevre sunması ve daha 
sağlıklı çözümler geliştirmesi gerektiği aşikârdır (Öztürk, 2018). Geliştirilecek bisiklet politikaları, sadece bisiklet ağlarının yapımını değil, aynı zamanda sürdürülebilirlik, sağlık, eşitlik ve erişim gibi güçlü bir bisiklet kültürünün oluşmasına da katk1da bulunur (Stephenson, 2015). Yapılan araştırmalar şehir genelinde bisiklet sürmeyi teşvik eden altyapı politikaları uygulayan şehirlerin, zamanla artan bisiklet hacimleriyle önemli avantajlar sağladıklarını bildirmiştir (Viola vd., 2010; WRI, 2013). Dünyada olduğu gibi ülkemizde de iklim değişikliğinin etkilerini hafifletmeye ve uyum sağlamaya yardımcı olmak için acil alternatif yatırımlar gereklidir. Gümüşhane'de tüm bu bilgiler 1şığında gerek yerel yönetimler gerek sivil toplum kuruluşları ile önerilen bisikletli ulaşım altyapısının gerçekleştirilerek, halkı teşvik etmenin birçok faydasının kısa ve uzun vadede görüleceği tahmin edilmektedir.

\section{Kaynaklar}

Akay, A. 2006. Ulaşımda Bisikletin Yeri ve Ankara Bilkent Koridorunda Bisiklet Yolu Önerisi. Gazi Üniversitesi Fen Bilimleri Enstitüsü, Yüksek Lisans Tezi, Ankara.

Andersen, L.B., Schnohr, P., Schroll, M., Hein, H.O., 2000. All-cause mortality associated with physical activity during leisure time, work, sports, and cycling to work. Arch. Intern. Med. 160, 1621-1628.

Ardahan, F. Mert, M., 2014 a. Bireyleri bisiklet kullanmaya motive eden faktörler ölçeğinin geliştirilmesi ve Türk popülasyonu için güvenirlilik geçerlilik çalışması, Akademik Sosyal Araştırmalar Dergisi, 2(1), 409-427.

Ardahan, F. Mert, M., 2014 b. Bisiklet Kullanan Bireylerin Profillerinin Belirlenmesi ve Bireyleri Bisiklet Kullanmaya Motive Eden Faktörlerin Çeşitli Demografik Değişkenlere Göre Değerlendirilmesi: Türkiye Örneği. Turkiye Klinikleri Journal of Sports Sciences, 6(2), 53-67.
Brög, W， John, G., 2001.Personalised Marketing - the Perth Success Story, In: Proceedings: Marketing Public Transport Conference, Auckland, New Zealand, 3 August 2001.

Burke, M.I., Bonham, J., 2010. Rethinking oil depletion: what role can cycling really play in dispersed cities? Aust. Plan. 47, 272-283.

Cervero, R., Duncan, M., 2003. Walking, bicycling, and urban landscapes: evidence from the San Francisco Bay Area. Am. J. Public Health 93, 1478-1483.

Cengiz, T., Kahvecioğlu, C., 2016. Sürdürülebilir Kent Ulaşımında Bisiklet Kullanımının Çanakkale Kent Merkezi Örneğinde İncelenmesi, Tekirdağ Ziraat Fakültesi Dergisi, 13 (02), 55-66.

Curtis, C., 2008. Planning for sustainable accessibility: the implementation challenge. Transp. Policy 15, 104-112.

Çalışkan, A., 2013, İstanbul İli, Sarıyer İlçesi, Zekeriyaköy-Uskumruköy-Kilyos

Koridorunda Bisiklet Yolu Uygulaması ve Kavşaklarda Güvenli Geçişe ilişkin Alternatiflerin Değerlendirilmesi, Yüksek Lisans Tezi, Bahçeşehir Üniversitesi, Fen Bilimleri Enstitüsü, İstanbul.

Çeyiz, S., Koçak, F., 2015. Ankara İli'nde Bisiklet Kullanan Bireylerin Karşılaştıkları Sorunlar ve Çözüm Önerileri, Mediterranean Journal of Humanities V/2, 203-221.

Çiftçi, Ö. 2006. Metropoliten Alanda Bisiklet Yolu Planlaması, Yüksek Lisans Tezi, İstanbul Teknik Üniversitesi, Fen Bilimleri Enstitüsü, İstanbul.

Collet, R., Madre, J.-L., Hivert, L., 2012. Spread of automobiles in France: what limits on car ownership and use? Econ. Stat. 457458, 1-17.

De Nazelle A, Nieuwenhuijsen MJ, Antó JM, Brauer M, Briggs D, Braun-Fahrlander C, Cavill N, Cooper AR, Desqueyroux H, Fruin $S$, et al., 2011. Improving health through policies that promote active travel: a review of evidence to support integrated health impact assessment. Environ Int., 37:766-777. 
Dupuy, G., 1999. From the 'magic circle' to 'automobile dependence': measurements and political implications. Transp. Policy 6, 1-17.

ECF, European Cyclist Federation, 2013. Calculating the economic benefits of cycling in EU-27.

Elbeyli, Ş. 2012, Kent içi Ulaşımda Bisikletin Konumu ve Şehirler İçin Bisiklet Ulaşımı Planlamas1: Sakarya Örneği, Yüksek Lisans Tezi, İstanbul Teknik Üniversitesi Fen Bilimleri Enstitüsü, İstanbul.

Environmental Protection Agency, 2011. US Greenhouse Gas Inventory Report.

Gaigne, C.; Riou, S.; Thisse, J. F.,2012. Are compact cities environmentally friendly?, J. Urban Econ., 72, 123-136.

Goetschi, T., Garrard, J., Giles-Corti, B., 2016. Cycling as a part of daily life: a review of health perspectives. Transp. Rev.: A Transnatl. Transdisciplinary J. 36, 45-71.

Hickman, R., Banister, D., 2007. Looking over the horizon: transport and reduced $\mathrm{CO} 2$ emissions in the UK by 2030. Transport Policy 14 (5), 377-387.

Hickman, R., Ashiru, O., Banister, D., 2010. Transport and climate change: simulating the options for carbon reduction in London. Transport Policy 17 (2), 110-125.

İmamoğlu, C.T., Ghasemlou, K.,Başaran, Ş., 2014. Bisiklet Yollarında Yol Güvenliği İncelemesi- Konya Örneği, 5. Karayolu Trafik Güvenliği Sempozyumu, 8-10 Kasım Ankara.

İyinam, Ş. ve İyinam A.F., 1999. Kentiçi ulaşımında bisiklet kullanımı. 2. Ulusal Kentsel Altyapı Sempozyumu, Adana, 18-20 Kasim.

Kaplan, H., 2005. Ekolojik Kentsel Ulaşımda Bisikletin Yeri, Bu Bağlamda Avrupa Kentlerinden Örneklerin İncelenmesi, Dünya Bisiklet Günü Sempozyumu, Konya, 3-16.

Kaplan, H., 2009. Ankara'da Çevre Dostu Ulaşım Tür ve Düzenlemelerinin Yeri-Yerel Yönetim Ulaşım Uygulamaları Yönünden Bir İrdeleme, Dosya11: Yerel Yönetimler:
Ulaşım ve $\mathrm{Su}$, TMMOB Mimarlar Odası Ankara Şubesi, ss. 55-70.

Koçak İ., Sari C., Özen H., 2005. Antalya da Kentiçi Ulaşımının Çeşitlendirilmesine Bir Öneri Bisiklet Kullanımı, Antalya Yöresinin İnşaat Mühendisliği Sorunları Kongresi, Antalya, TÜRKIYE, , cilt.2, ss.497-511.

Koçak, F., 2016. Türkiye'de bisiklet kullanımı: Bisiklet kullanma nedenleri ve elde edilen faydalar. Journal of Human Sciences, 13(3), 5760-5771.

Levent, M.A., 2014. Kent İçi Sürdürülebilir Ulaşım Çözümleri: Bisiklet İle Kent İçin Ulaşım: Brüksel, Konya Ve Kayseri Örnekleri, 5. Karayolu Trafik Güvenliği Sempozyumu, 8-10 Kasım Ankara.

Mert, K. ve Öcalır, V.E., 2010. Konya'da bisiklet ulaşımı: Planlama ve uygulama süreçlerinin karşılaştırılması. METU JFA, 27:1, sf. 223-240.

Milne, A., Melin, M., 2014. Bicycling and Walking in the United States: 2014, Benchmarking Report. Alliance for Bicycling and Walking. http://www. bikewalkalliance.org/storage/documents/repo rts/2014BenchmarkingReport.pdf

Newman, P., Kenworthy, J., 1989. Cities and Automobile Dependence. Gower Technical, Aldershot.

Oja, P., Titze, S., Bauman, A., de Geus, B., Krenn, P., Reger-Nash, B., \& Kohlberger, T. (2011). Health benefits of cycling: a systematic review. Scandinavian Journal of Medicine \& Science in Sports, 21(4),496509.https://doi.org /10.1111 /j.16000838.2011.01299.x.

Öncü E.1990. Toplu taşımın Tamamlayıcısı Olarak Bisiklet, Şehir Plancıları Odası Planlama Dergisi, 90,1-2, Ankara.

Öztürk, Ö.F., 2018. Gümüşhane İli İçin Bisiklet Ulaşımı Planlaması, Yüksek Lisans Tezi, Gümüşhane Ünv., Fen Bil. Ens., Gümüşhane, 156.

Racioppi, F., Dora, C., Rutter, H., 2013. Urban Settings and Opportunities for Healthy Lifestyles: rediscovering walking and cycling 
and understanding their health benefits. Built Environ. 31, 302-314.

Reynolds, C., Winters, M., Ries, F., Gouge, B., 2010. Active transportation in urban areas: Exploring health benefits and risks. National Collaboration Centre for Environmental Health.

Rojas-Rueda, D., de Nazelle, A., Tainio, M., Nieuwenhuijsen, M.J., 2011. The health risks and benefits of cycling in urban environments compared with car use: health impact assessment study. Br. Med. J. 343.

Stephenson, S., 2015. A Comparative Analysis of Bicycle Cultures in the United States and The Netherlands. Claremont Colleges.

TÜİK, 2016. Adrese Dayalı Nüfus Kayıt Sistemi Sonuçları, TÜİK, Ankara.

Ulvi H. 2002. Kentiçi Ulaşımda Bisiklet Kullanımı Konya Örneğinde Bir Araştırma, Yüksek Lisans Tezi, Selçuk Üniversitesi, Fen Bilimleri Enstitüsü, Konya.

Uslu, C., Altunkasa, M.F., Boyacigil, O., Konakl1, N., 2009. Adana kuzeybatı üst kentsel gelişme alanında bisikletli bağlantı olanaklarının değerlendirilmesinde çözümlemeli bir yaklaşım. Ekoloji 70, 57-66.

United Nations (UN), Department of Economic and Social Affairs. Population Division, 2014. World Urbanization Prospects: The 2014 Revision, Highlights (st/esa/ser.A/352). United Nations (UN).

Uz, V.E. ve Karaşahin, M., 2004. Kentiçi Ulaşımda Bisiklet. Türkiye Mühendislik Haberleri, say1 429, sf 41-46.

Wen, C.P., Wai, J.P.M., Tsai, M.K., Yang, Y.C., Cheng, T.Y.D., Lee, M.-C., Chan, H.T., Tsao, C.K., Tsai, S.P., et al., 2011. Minimum amount of physical activity for reduced mortality and extended life expectancy: a prospective cohort study. Lancet 378, 1244 1253.

Viola, R., Roe, M., Shin, H., 2010. The New York City Pedestrian Safety Study and Action Plan. New York City Department of Transportation.
WRI, 2013. Saving lives with sustainable transport. Traffic safety impacts of sustainable transport policies. Word Resources Institute.

Woodcock, J., Edwards, P., Tonne, C., Armstrong, B.G., Ashiru, O., Banister, D., et al., 2009. Public health benefits of strategies to reduce greenhouse-gas emissions: urban land transport. Lancet 374, 1930-1943, https://doi.org/10.1016 /S01406736(09)61714-1.

Yakar, F., Bakır, M.Y., Başdemir, H., 2017. Gaziosmanpaşa Üniversitesi Taşlıçiftlik Yerleşkesinde Bisikletli Ulaşım Altyapısı Oluşturulması, Gaziosmanpaşa Bilimsel Araştırma Dergisi (GBAD), 6 (3), 12-25. 